\title{
Regulation of dimethylarginine dimethylaminohydrolase 2 expression by NF-кB acetylation
}

\author{
JIAQI LI ${ }^{1}, \mathrm{LU} \mathrm{SUN}^{1,2}$ and YINGHUI LI ${ }^{1}$ \\ ${ }^{1}$ Department of Medical Genetics, School of Life Science, China Medical University, Shenyang, Liaoning 110122; \\ ${ }^{2}$ Department of Clinical Genetics, Shengjing Hospital, China Medical University, Shenyang, Liaoning 110004, P.R. China
}

Received July 5, 2020; Accepted October 8, 2020

DOI: $10.3892 / \mathrm{etm} .2020 .9546$

\begin{abstract}
Nitric oxide (NO) serves a crucial role in the kidney and is synthesized by NO synthase (NOS). Asymmetrical dimethylarginine is an endogenous inhibitor of NOS that is metabolized by dimethylarginine dimethylaminohydrolase (DDAH). To investigate the role of acetylation in DDAH2 expression, 293 cells were treated with trichostatin A (TSA), a deacetylase inhibitor and the mRNA and protein levels were assessed using quantitative PCR and western blotting respectively. Its promoter activity was detected using a luciferase assay. The effect of TSA on NF- $\kappa$ B acetylation was tested after immunoprecipitation. The binding of $\mathrm{NF}-\kappa \mathrm{B}$ to the DDAH2 promoter was analyzed using an electrophoretic mobility shift assay and chromatin immunoprecipitation. TSA upregulated DDAH2 expression and transcriptional activity of the DDAH2 promoter through a NF- $\kappa \mathrm{B}$ responsive element, which is located at the -1582 to -1573 position of the DDAH2 promoter. Furthermore, TSA treatment promoted NF- $\kappa \mathrm{B}$ acetylation, resulting in enhanced $N F-\kappa B$ binding affinity to its binding site both in vitro and in vivo. Taken together, the present study demonstrated that NF- $\kappa \mathrm{B}$ acetylation upregulated DDAH2 expression by enhancing the binding ability of $\mathrm{NF}-\kappa \mathrm{B}$ to the DDAH2 promoter, resulting in increased promoter activity. The results provided a possible mechanism underlying the regulation of $\mathrm{NO}$ production in renal cells and a potential target for treating certain $\mathrm{NO}$-associated renal disorders.
\end{abstract}

Correspondence to: Dr Yinghui Li, Department of Medical Genetics, School of Life Science, China Medical University, 77 Puhe Road, Shenyang North New Area, Shenyang, Liaoning 110122, P.R. China

E-mail: yhli@cmu.edu.cn

Abbreviations: ADMA, asymmetrical dimethylarginine; ChIP, chromatin immunoprecipitation; DDAH, dimethylarginine dimethylaminohydrolase; EMSA, electrophoretic mobility shift assay; NO, nitric oxide; NOS, NO synthase; iNOS, inducible NOS; nNOS, neuronal NOS; TSA, trichostatin A

Key words: dimethylarginine dimethylaminohydrolase 2, NF-кB, acetylation, nitric oxide

\section{Introduction}

Nitric oxide (NO) is a signaling molecule that plays a crucial role in the kidney and participates in a number of physiological processes, including ion transportation and blood pressure regulation (1). It has been previously reported that NO inhibits transepithelial $\mathrm{Na}+$ reabsorption and antidiuretic hormone-stimulated osmotic water permeability $(2,3)$. Therefore, modulation of NO levels in the kidney is of importance. NO is synthesized from L-arginine by three isoforms of NO synthases (NOS), namely neuronal (nNOS), inducible (iNOS) and endothelial. Asymmetric dimethylarginine (ADMA) is an endogenous analog of L-arginine that can attenuate the function of NOS and has been shown to be harmful for the kidney (4). ADMA exhibits a causative role in the development of kidney injury in terms of renal fibrosis and is considered to be a predictive risk factor for diabetic nephropathy (5). ADMA is metabolized by dimethylarginine dimethylaminohydrolases (DDAHs) in vivo that can exist as type 1 and 2 isoforms. The kidney serves a role in eliminating ADMA, such that the kidney cortex contains the highest concentration of DDAH enzymes among all organs (6). The two isoforms of DDAH are expressed in a tissue-specific manner. Specifically, DDAH-2 is expressed in the macula densa and distal nephron regions of the kidney (6-8).

NOS and DDAH systems are important factors in determining NO production. Therefore, their expression regulates NO levels. Although mechanism underlying the regulation of NOS expression has been widely defined (9), reports on the regulatory mechanisms underlying DDAH expression are limited, with the majority of the previous studies referring to methylation. Hypermethylation of the DDAH2 promoter was associated with DDAH2 downregulation in human umbilical vein endothelial cells and the rat corpora cavernosa, whereas the inhibition of methylation using 5'-aza-2'-deoxycytidine enhanced DDAH2 expression in undifferentiated cells of trophoblast cell lineage (10-12). Acetylation is an important epigenetic modification that has been reported to regulate NOS expression by various mechanisms $(13,14)$. To the best of our knowledge, mechanistically, only Tomikawa et al (12) previously reported that histone acetylation regulated the expression of DDAH2 in trophoblast stem cells and was involved in the regulation of cell differentiation. However, the accurate mechanism has not been fully elucidated. 
$\mathrm{NF}-\kappa \mathrm{B}$ is a DNA sequence-specific transcription factor that is subject to acetylation. The NF- $\kappa \mathrm{B}$ acetylation status may affect its DNA binding affinity, transcriptional activity and protein interactions, thereby indirectly regulating the transactivation of numerous genes (15-18). A previous study and other reports demonstrated that $\mathrm{NF}-\kappa \mathrm{B}$ acetylation could regulate the expression of NOS genes $(19,20)$. Therefore, the present study hypothesized that NF- $\kappa \mathrm{B}$ acetylation may also be involved in regulating DDAH2 expression, resulting in the changes in both NOS and DDAH levels in turn acting as an important factor in modulating NO production. Trichostatin A (TSA), a deacetylase inhibitor, was used to induce acetylation in 293 cells to assess the effect of acetylation on DDAH2 expression and its mechanisms.

\section{Materials and methods}

Cell culture and treatment. 293 cells, purchased from the Cell Bank of Type Culture Collection of the Chinese Academy of Sciences, were cultured in DMEM (Thermo Fisher Scientific, Inc.) supplemented with $15 \% \mathrm{FBS}$ in a humidified atmosphere containing $5 \% \mathrm{CO}_{2}$ at $37^{\circ} \mathrm{C}$. Subsequently, $24 \mathrm{~h}$ after seeding, cells were treated with $250 \mathrm{ng} / \mathrm{ml}$ TSA (Sigma-Aldrich; Merck KGaA) at $37^{\circ} \mathrm{C}$ for $24 \mathrm{~h}$ or transfected with indicated plasmids and collected $24 \mathrm{~h}$ after. All cultures were tested for mycoplasma.

Reverse transcription-quantitative PCR (RT-qPCR). Total RNA was extracted from 293 cells using a TRIzol ${ }^{\circledR}$ reagent (Thermo Fisher Scientific, Inc.) and cDNA was synthesized using the Reverse Transcription System (cat. no. A3500; Promega Corporation) according to the manufacturer's protocols. qPCR was performed in an Applied Biosystems 7500 Real-Time PCR System (Applied Biosystems; Thermo Fisher Scientific, Inc.) using a total reaction volume of $20 \mu \mathrm{l}$ containing 1X SYBR ${ }^{\mathrm{TM}}$-Green PCR master mix (Thermo Fisher Scientific, Inc.), $10 \mathrm{ng}$ cDNA and $100 \mathrm{nmol} / \mathrm{l}$ forward and reverse primers. The sequences of the intron-spanning primers used were as follows: DDAH2 forward, 5'-TCTCTT TCTTCGTCCTGGGT-3' and reverse, 5'-CACAGGTAC CAGGGTGACAT-3' and $\beta$-actin forward, 5'-CCGTCTTCC CCTCCATCG-3' and reverse, 5'-GTCCCAGTTGGTGAC GATGC-3'. Thermocycling conditions were $95^{\circ} \mathrm{C}$ for $3 \mathrm{~min}$ followed by $95^{\circ} \mathrm{C}$ for $10 \mathrm{sec}$ and $60^{\circ} \mathrm{C}$ for $60 \mathrm{sec}$ for 40 cycles. Dissociation curves were generated to ensure that a single and specific product was amplified. Cycle threshold values $(\mathrm{Ct})$ were analyzed using the SDS 2.4 software (Thermo Fisher Scientific, Inc.) and quantification of the relative DDAH2 expression was performed using the $2^{-\Delta \Delta \mathrm{Cq}}$ method (21) with the $\beta$-actin transcript serving as an internal control.

Western blot analysis. Whole cell lysate was prepared from 293 cells using RIPA buffer (Thermo Fisher Scientific, Inc.). Protein was quantified using the DC Protein assay (Bio-Rad Laboratories, Inc.) following the manufacturer's instructions. In total, $25 \mu \mathrm{g}$ of each sample was subjected to $10 \%$ SDS-PAGE and transferred onto PVDF membranes (Bio-Rad Laboratories, Inc.). Subsequently, the membranes were blocked with 5\% non-fat dry milk in TBS containing $0.1 \%$ Tween-20 at room temperature for $1 \mathrm{~h}$ and incubated with primary antibodies at $4^{\circ} \mathrm{C}$ overnight, followed by incubation with an horseradish peroxidase-conjugated secondary antibody (cat. no. sc-2004 or sc-2005; 1:2,500 dilution; Santa Cruz Biotechnology, Inc.) at room temperature for $2 \mathrm{~h}$. The protein bands were detected with an enhanced chemiluminescence detection kit (Bio-Rad Laboratories, Inc.) and quantified with Quantity One 1-D Analysis Software version 4.6.8 (Bio-Rad Laboratories, Inc.). The primary antibodies used were as follows: Anti-DDAH2 (cat. no. sc-32859; 1:500 dilution; Santa Cruz Biotechnology, Inc.), anti-p65 (cat. no. sc-8008; 1:500 dilution; Santa Cruz Biotechnology, Inc.), anti- $\beta$-actin (cat. no. 12262S; 1:2,500 dilution; Cell Signaling Technology, Inc.), monoclonal antibody against acetylated lysine (cat. no. 9681S; 1:1,000 dilution, Cell Signaling Technology, Inc.) and anti-Lamin B1 antibody (cat. no. 33-2000; 1:500 dilution; Thermo Fisher Scientific, Inc.).

Analysis of DDAH2 promoter and plasmid construction. A 2 kbp (from -1983 to +17 ) sequence of the DDAH2 promoter was analyzed using the Prediction of transcription factor binding sites analysis of Alibaba-2.1 (default values for all parameters) and Matrix Search for Transcription Factor Binding Sites analysis with minimal false negatives of Match-1.0 Public software (http://www.gene-regulation.com). The DDAH2 promoter fragment containing a potential $\mathrm{NF}-\kappa \mathrm{B}$ responsive element (located between-1582 and -1573 positions) was cloned into pMD18-T vector (Takara Bio, Inc.), digested with SacI and HindIII restriction enzymes (New England Biolabs, Inc.) and then subcloned into SacI/HindIII site of the pGL3_Basic vector (Promega Corporation) to construct the pGL_1983 wild-type (wt) plasmid. In addition, a plasmid encompassing a mutated NF- $\kappa \mathrm{B}$ binding site (pGL_1983mut) was generated using the Q5 site-directed mutagenesis kit following the manufacturer's protocol (New England BioLabs, Inc.) to change two corresponding $G$ and $A$ residues to $T$ (sequence was changed from GGGCAGGGAA to GGG CAGGTAT,) to abolish the potential NF- $\mathrm{NB}$ element. All constructs were confirmed by Sanger sequencing, as previously described (22).

Luciferase assay. 293 cells were seeded at 10,000 cells/well into 96-well plates, grown to 60-70\% confluence and transiently transfected with the plasmids using the Lipofectamine ${ }^{\circledR} 2000$ reagent (Thermo Fisher Scientific, Inc.). To normalize transfection efficiency, a pRL-TK plasmid (Promega Corporation) containing a cDNA encoding Renilla luciferase was used as an internal control. A total of $0.5 \mu \mathrm{g}$ either of the pGL constructs (pGL_1983wt, pGL_1983mut or pGL3-Basic) and $0.05 \mu \mathrm{g}$ pRL-TK were co-transfected into the 293 cells. Following incubation for $6 \mathrm{~h}$, cells were treated with TSA $(250 \mathrm{ng} / \mathrm{ml}$ ) for $24 \mathrm{~h}$. The luciferase activity was determined using the Dual-Luciferase ${ }^{\circledR}$ Reporter assay system following the manufacturer's instructions (Promega Corporation) using a Lumat LB 9507 luminometer (Berthold Technologies, GmbH). Relative luciferase activity was expressed as the ratio of firefly activity to that of Renilla.

Immunoprecipitation. Nuclear extracts were prepared from 293 cells using the Nuclear Extract Kit (cat. no. 40010; Active Motif Inc.) following the manufacturer's protocol and the 
concentration was quantified with DC Protein Assay kits (cat. no. 5000112; Bio-Rad Laboratories, Inc.) following the manufacturer's instructions. In total, $10 \mu 1$ antibody against p65 (cat.no.sc-8008; Santa Cruz Biotechnology,Inc.) was incubated with $400 \mu \mathrm{g}$ nuclear extract at $4^{\circ} \mathrm{C}$ overnight. Subsequently, $20 \mu \mathrm{l}$ protein $\mathrm{A} / \mathrm{G}$-agarose beads (cat. no. sc-2003; Santa Cruz Biotechnology, Inc.) were added and incubated with the lysates at $4^{\circ} \mathrm{C}$ for $2 \mathrm{~h}$ to collect the immunoprecipitated proteins before the samples were centrifuged at 1,000 $\mathrm{x}$ for $5 \mathrm{~min}$ and extensively washed with buffer containing $50 \mathrm{mM}$ Tris (pH 8.0), $150 \mathrm{mM} \mathrm{NaCl}, 1 \mathrm{mM}$ EDTA and 0.5\% NP-40. The immunoprecipitated proteins were then mixed with SDS loading buffer, boiled for $5 \mathrm{~min}$ and analyzed by SDS-PAGE and western blot analysis using a monoclonal antibody against acetylated lysine (Cell Signaling Technology, Inc.).

Electrophoretic mobility shift assay (EMSA). Nuclear extracts were first prepared from 293 cells. The oligonucleotide probes (synthesized by Sangon Biotech Co., Ltd.) used were: i) NF-кB consensus, 5'-AGTTGAGGGGACTTTCCCAGGC-3' and its complementary fragment; ii) for wild-type (WT) $\mathrm{NF}-\kappa \mathrm{B}$, 5'-GGGCAGGGAATCCTGGAG-3' and its complementary fragment; and iii) for mutant (MUT) NF- $\mathrm{B}, 5$ '-GGGCAG GTATTCCTGGAG-3' (mutations underlined) and its complementary fragment. The probes were labeled using the Biotin 3' End Labeling Kit (cat. no. 20160, Thermo Fisher Scientific, Inc.) following the details from the manufacturer. EMSA was performed using the Lightshift ${ }^{\mathrm{TM}}$ Chemiluminescent EMSA kit (Thermo Fisher Scientific, Inc.) according to the manufacturer's protocol. Next, $10 \mu \mathrm{g}$ nuclear extract and $25 \mathrm{pmol}$ probe were used in binding reaction. For competition assays, nuclear extract was pre-incubated with a 100-fold excess of the unlabeled WT or MUT competitors with the same sequence as indicated above at $4^{\circ} \mathrm{C}$ for $30 \mathrm{~min}$. For the supershift reaction, $1 \mu \mathrm{g}$ anti-p65 antibody (cat. no. sc-8008; Santa Cruz Biotechnology, Inc.) or normal IgG (cat. no. sc-3888; Santa Cruz Biotechnology, Inc.) was pre-incubated with $10 \mu \mathrm{g}$ nuclear extracts at $4^{\circ} \mathrm{C}$ for $30 \mathrm{~min}$. The protein-DNA complexes were separated by electrophoresis on a $6 \%$ non-denaturing acrylamide gel in $0.5 \mathrm{X}$ TBE before transferal onto positively charged nylon membranes and visualized using streptavidin-horseradish peroxidase (Thermo Fisher Scientific, Inc.), followed by chemiluminescent detection (Thermo Fisher Scientific, Inc.) on ChemiDoc Imaging Systems (Bio-Rad Laboratories, Inc.).

Chromatin immunoprecipitation (ChIP). Cultured 293 cells were treated with $1 \%$ formaldehyde and incubated at $37^{\circ} \mathrm{C}$ for $20 \mathrm{~min}$. Cells were then harvested, resuspended in lysis buffer (1\% SDS, $10 \mathrm{mmol} / 1$ EDTA, $50 \mathrm{mmol} / 1$ Tris-HCl, $\mathrm{pH} \mathrm{8.1),}$ incubated at $4^{\circ} \mathrm{C}$ for $10 \mathrm{~min}$ and sonicated at $20 \mathrm{kHz}$ frequency output for $10 \mathrm{~min}$ on ice with cycles of $15 \mathrm{sec}$ on/15 sec off to generate DNA fragments $100-300 \mathrm{bp}$ in length along with bound proteins. In total, $33 \%$ of the lysate was used as the DNA input control. The remaining lysate was diluted 10 -fold, where $50 \%$ of the sample was incubated with $20 \mathrm{ng} / \mu \mathrm{l}$ specific p65 antibody and the remaining half was incubated with normal rabbit $\mathrm{IgG}$ at $4^{\circ} \mathrm{C}$ overnight. Immunoprecipitated complexes were then collected by incubating with $20 \mu \mathrm{l}$ protein $\mathrm{A} / \mathrm{G}$-agarose beads at $4^{\circ} \mathrm{C}$ for $1 \mathrm{~h}$ and centrifuged at $1,000 \mathrm{x} \mathrm{g}$ for $5 \mathrm{~min}$ at $4^{\circ} \mathrm{C}$. The beads were extensively washed with low salt immune complex wash buffer (0.1\% SDS, 1\% Triton X-100, 2 mmol/1 EDTA, 20 mmol/l Tris-Cl, pH 8.1 and $150 \mathrm{mmol} / 1 \mathrm{NaCl}$ ), high salt immune complex wash buffer (the same components apart from the use of $500 \mathrm{mmol} / \mathrm{l} \mathrm{NaCl}$ ) and Tris-EDTA, pH 8.0 successively, and incubated at room temperature for $20 \mathrm{~min}$. Precipitates were eluted with elution buffer $\left(0.1 \%\right.$ SDS and $\left.0.1 \mathrm{~mol} / 1 \mathrm{NaHCO}_{3}\right)$ and cross-linking of protein-DNA complexes was reversed following incubation at $65^{\circ} \mathrm{C}$ for $5 \mathrm{~h}$. DNA was then extracted using phenol/chloroform, as previously described (23). qPCR was performed using a total reaction volume of $20 \mu \mathrm{l}$ containing $1 \mathrm{X} \mathrm{SYBR}^{\mathrm{TM}}$ Green PCR master mix (Thermo Fisher Scientific, Inc.) with the following pairs of primers: i) Forward, 5'-TGGTGGTTTCCS CATTGCTA-3' and reverse, 5'-ACTCATCCCACCCCACAA TA-3' to detect the binding capacity of p65 to the potential $\mathrm{NF}-\kappa \mathrm{B}$ element; ii) detection of the DDAH2 promoter region without any potential NF- $\kappa \mathrm{B}$ element was used as a negative control with the following pair of primers: Forward, 5'-GGG TGGGTCAGTGATCTTGA-3' and reverse, 5'-TAGACCTCA GAACAGCGCAA-3'; and iii) a previously identified NF- $\kappa \mathrm{B}$ element within the nNOS promoter (19) was used as a positive control, using the following primers: Forward, 5'-GCAAGA CGATCTGAAAAGCA-3' and reverse, 5'-CTGGCTCTG GGTGATTTGAT-3'. Thermocycling conditions were $95^{\circ} \mathrm{C}$ for $3 \mathrm{~min}$ followed by $95^{\circ} \mathrm{C}$ for $10 \mathrm{sec}$ and $61^{\circ} \mathrm{C}$ for $60 \mathrm{sec}$ for 40 cycles. The enrichment of immunoprecipitated DNA was calculated relative to the input DNA using the $2^{-\Delta \Delta C q}$ method (24).

Statistical analysis. All experiments were performed at least three times. Results are expressed as the mean \pm standard deviation from three independent experiments. SPSS 22.0 (IBM Corp.) was used for statistical analyses. $\mathrm{P}<0.05$ was considered to indicate a statistically significant difference. Differences between DDAH2 mRNA and protein expression levels were analyzed using one-way ANOVA with Tukey's multiple comparison post hoc test. Luciferase activity and ChIP results were analyzed using two-way ANOVA with Sidak correction and Tukey's multiple comparison post hoc test. The levels of $N F-\kappa B$ acetylation between two groups were compared using an unpaired two-tailed Student's t-test.

\section{Results}

TSA upregulates DDAH2 expression. TSA is a deacetylase inhibitor that can induce the acetylation of both histones and non-histone proteins (25). Therefore, 293 cells were treated with TSA to evaluate the effect of acetylation on DDAH2 expression. A total of three transcripts of the human $D D A H 2$ gene were identified, each with different transcription start sites (Fig. 1A). However, all transcripts share the same 858-bp open reading frame encoding a 285 -amino acid protein. Therefore, qPCR assays were performed to evaluate the effect of TSA on total DDAH2 mRNA using a pair of intron-spanning primers targeting the coding sequence (Fig. 1A). Compared with that in the untreated control cells, DDAH2 mRNA was significantly increased, by 2.2-fold that of untreated control following treatment with TSA for $24 \mathrm{~h}$ (Fig. 1B). 
A
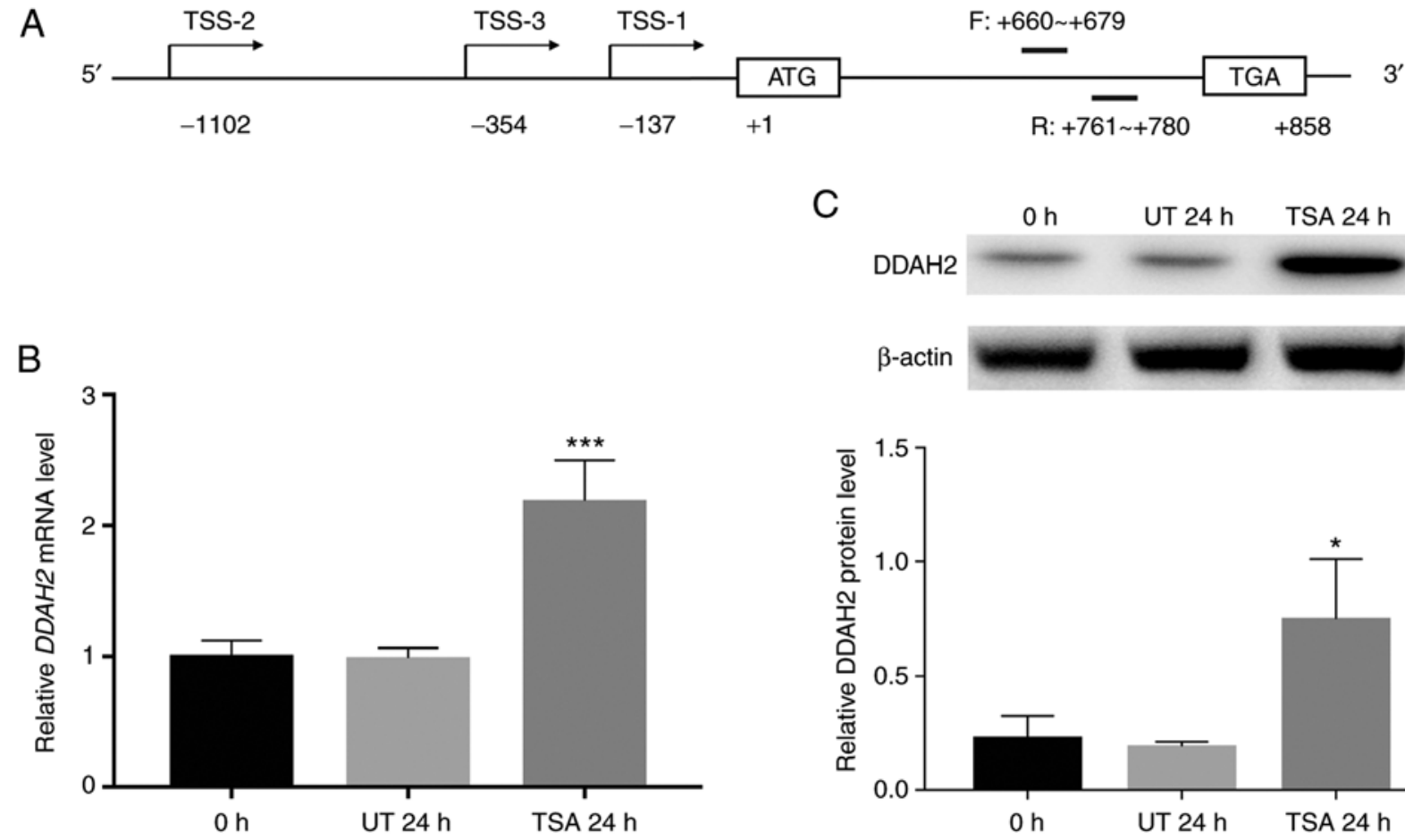

C

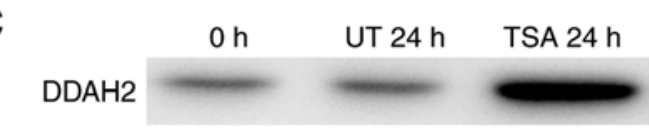

B
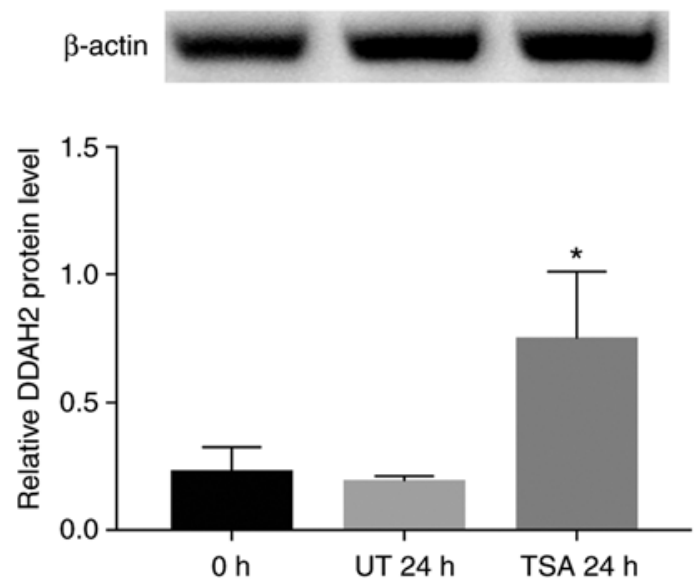

Figure 1. DDAH2 expression is increased by TSA. (A) Structure of human DDAH2 gene. (B) Relative DDAH2 mRNA expression as measured using reverse transcription-quantitative PCR. (C) Immunoblots and densitometry analysis of DDAH2 protein expression. Relative DDAH2 protein level represents the ratio of the densitometry of DDAH2 normalized to that of $\beta$-actin. $\mathrm{n}=3 .{ }^{*} \mathrm{P}<0.05,{ }^{* * * *} \mathrm{P}<0.001$ vs. $24 \mathrm{~h}$ UT. DDAH2, dimethylarginine dimethylaminohydrolase 2 ; TSS, transcription start site; F, forward primer; R, reverse primer; 0 h, before treatment; UT, untreated; TSA, trichostatin A.

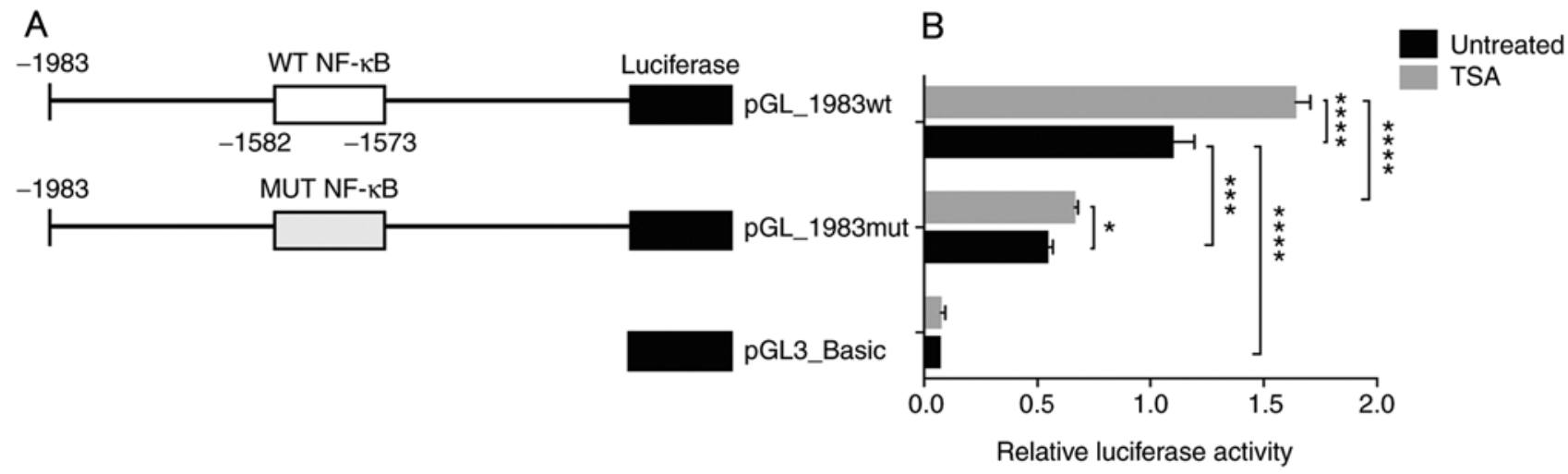

Figure 2.DDAH2 promoter activity is upregulated by TSA treatment through an NF-кB responsive element. (A) Structure of the pGL3_Basic-based luciferase reporter assay system. pGL_1983wt is the plasmid containing the DDAH2 promoter with the WT NF- $\kappa$ B responsive element, whereas pGL_1983mut is the MUT version of pGL_1983wt containing the mutated NF- $\kappa$ B site. (B) Promoter activities under untreated or TSA-treated conditions of the corresponding plasmids. $\mathrm{n}=3$. ${ }^{*} \mathrm{P}<0.05,{ }^{* * *} \mathrm{P}<0.001$ and ${ }^{* * * *} \mathrm{P}<0.0001$. DDAH2, dimethylarginine dimethylaminohydrolase 2; TSA, trichostatin A; WT, wild-type; MUT, mutant.

Western blotting results showed that in TSA-treated cells, DDAH2 protein levels were also significantly upregulated, by 3.2-fold that of untreated control (Fig. 1C).

DDAH2 promoter activity is upregulated by TSA through an $\mathrm{NF}-\kappa \mathrm{B}$ responsive element. $\mathrm{NF}-\kappa \mathrm{B}$ is involved in several cellular functions, including the initiation and propagation of inflammatory and immune responses, which have also been reported to serve critical roles in the kidney $(26,27)$. In addition, it was previously shown that acetylation regulates nNOS gene expression via NF-kB (19). Therefore, the present study aimed to investigate whether the TSA-induced DDAH2 expression was also NF- $\mathrm{kB}$-dependent, upstream of the strong effects on NO synthesis. Therefore, a 2-kbp DDAH2 sequence upstream of the start codon (from -1983 to +17) was analyzed using bioinformatics tools. The analysis predicted a potential NF- $\mathrm{BB}$ binding site located at -1582 to -1573 (Fig. S1; produced using Alibaba-2.1). This site lies upstream of the transcription start sites in all three transcripts, indicating its importance in regulating DDAH2 transcription activation.

To verify the role of this potential NF- $\kappa B$ element, luciferase reporter vectors of the DDAH2 promoter were constructed, containing either WT NF- $\kappa$ B or MUT NF- $\kappa$ B element. The MUT NF- $\kappa B$ element was produced by changing the two corresponding $\mathrm{G}$ and $\mathrm{A}$ residues to $\mathrm{T}$ (GGGCAGGTAT). These vectors were subsequently named pGL_1983wt and 
pGL_1983mut (Fig. 2A). Alibaba-2.1 analysis revealed that the potential NF- $\kappa$ B element was abolished, showing no NF- $\kappa \mathrm{B}$ binding after the substitution (Fig. S2). Furthermore, as shown in Fig. 2B, luciferase assay results demonstrated that under basal conditions, pGL_1983wt exhibited increased transcriptional activity compared with that by pGL3_Basic. However, mutation in the NF- $\kappa \mathrm{B}$ site (pGL_1983mut) markedly reduced this activity compared with pGL_1983wt in untreated cells. Treatment with TSA significantly increased the activity of pGL_1983wt compared with that of untreated control, by 1.6-fold. Also, after TSA treatment, luciferase activity from the pGL_1983mut plasmid was significantly lower compared with that exhibited by pGL_1983wt. However, TSA treatment exhibited a much less obvious although significant effect (1.2-fold untreated control) on the activity of the pGL1983 mut plasmid. These results suggested that the potential NF- $\mathrm{B}$ element could serve a role in the transactivation of the DDAH2 promoter, such that the TSA-mediated induction of DDAH2 expression was at least partially promoted by this element.

$N F-\kappa B$ binding affinity to DDAH2 promoter is enhanced by TSA-induced $N F-\kappa B$ acetylation. It has been previously reported that $\mathrm{NF}-\kappa \mathrm{B}$ acetylation is associated with several renal diseases. Enhanced $\mathrm{NF}-\kappa \mathrm{B}$ acetylation was found in diabetic nephropathy $(28,29)$ and cisplatin-induced p65 acetylation resulted in renal proximal tubule cell injury (30). Therefore, the acetylation of NF- $\mathrm{NB}$ was assessed in 293 cell lysates. Nuclear extracts were immunoprecipitated using a p65-specific antibody, where acetylated protein was detected by western blotting using a monoclonal antibody specific for acetylated lysine. The results showed that under basal conditions, p65 was acetylated, which was significantly increased following TSA treatment, without any notable effects on total p65 protein levels (Fig. 3).

The acetylation status of the transcription factors can influence their DNA binding affinity (19). To reveal the mechanism underlying the effect of TSA on DDAH2 upregulation in its $\mathrm{NF}-\kappa \mathrm{B}$ element (from -1582 to -1573 ), the binding affinity of $\mathrm{NF}-\kappa \mathrm{B}$ to the DDAH2 response element was assessed in vitro using EMSA. WT probe (lane 3) formed a complex with the nuclear extracts isolated from 293 cells, in a similar manner to that of the consensus probe (lane 2; Fig. 4A). Following site-directed mutagenesis on the $\mathrm{NF}-\kappa \mathrm{B}$ element by changing the two corresponding $\mathrm{G}$ and $\mathrm{A}$ residues to $\mathrm{T}$ (MUT probe; 5'-GGGCAGGTATTCCTGGAG-3'), binding ability with nuclear extracts from 293 cells disappeared (lane 6). The WT probe-nuclear extract complex was found to be displaced by unlabeled WT competitors (lane 4) but not with unlabeled mutant competitors (lane 5). In addition, the binding ability of NF- $\kappa \mathrm{B}$ to its responsive element (WT probe) was blocked by a 65 -specific antibody, indicating when the nuclear extract was pre-incubated with the antibody, p65 bound to its specific antibody, which blocked its binding to the probe. Whereas, when a normal IgG was used (Fig. 4B), no evident blocking effect was seen, confirming the specificity of $\mathrm{NF}-\kappa \mathrm{B}$ binding. Notable, binding was markedly enhanced in TSA-treated cells (Fig. 4C).

Furthermore, ChIP assay was subsequently performed to measure $\mathrm{NF}-\kappa \mathrm{B}$ binding affinity to the DDAH2 promoter. Chromatin from untreated and TSA-treated cells was

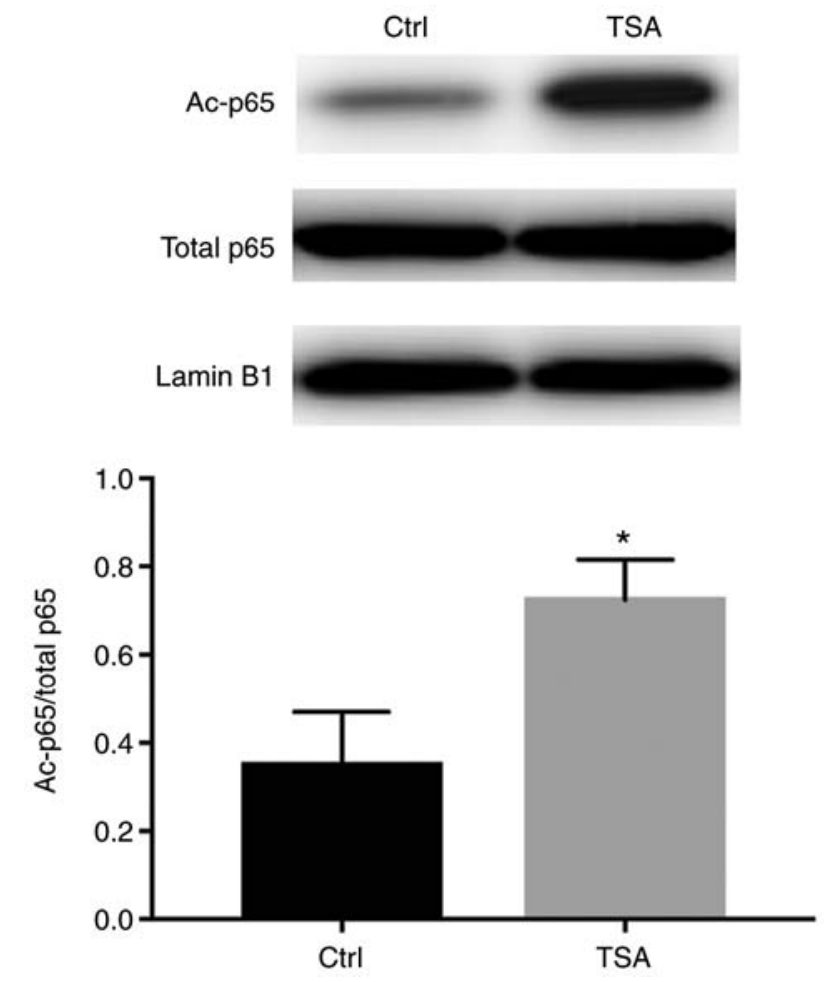

Figure 3. p65 acetylation is upregulated by TSA. Immunoblotting results of Ac-p65 and total p65 protein level in the nuclear extract of untreated or TSA-treated 293 cells. Lamin B1 was used as loading control. $n=3$. ${ }^{*} \mathrm{P}<0.05$ vs. Ctrl. Ctrl, control; DDAH2, dimethylarginine dimethylaminohydrolase 2; TSA, trichostatin A; Ac-, acetylated.

immunoprecipitated using the p65 antibody. A DDAH2 promoter fragment containing the NF- $\kappa \mathrm{B}$ element was amplified by qPCR, whilst DDAH2 promoter fragments without any potential NF- $\kappa \mathrm{B}$ elements and a nNOS gene promoter region with an NF- $\kappa B$ element (19) served as negative and positive controls, respectively. The results showed that $\mathrm{p} 65$ specifically bound to the DDAH2 promoter encompassing the WT NF- $\kappa \mathrm{B}$ element, whilst immunoprecipitation using normal IgG did not show evident binding (Fig. 5). This was demonstrated by the significantly increased number of DDAH2 promoter templates in p65 antibody-incubated samples compared with those in IgG-incubated samples prior to TSA treatment (Fig. 5). In addition, TSA significantly augmented p65 binding to the NF- $\kappa \mathrm{B}$ responsive element within the DDAH2 promoter (Fig. 5). These findings indicated that NF- $\kappa \mathrm{B}$ could specifically bind to the NF- $\kappa \mathrm{B}$ responsive element located at the -1582 to -1573 region of the DDAH2 promoter, such that p65 acetylation significantly enhanced this binding affinity to this element.

\section{Discussion}

The present study demonstrated that DDAH2 mRNA and protein expression was upregulated in renal cells following $\mathrm{NF}-\kappa \mathrm{B}$ acetylation by enhancing its binding to an $\mathrm{NF}-\kappa \mathrm{B}$ element upstream of all three DDAH2 transcripts, resulting in increased promoter activity.

Reversible protein acetylation has been implicated in the transcriptional regulation of numerous genes. Histone acetylation was first shown to affect gene expression by modifying the degree of chromatin condensation $(31,32)$. A growing number 

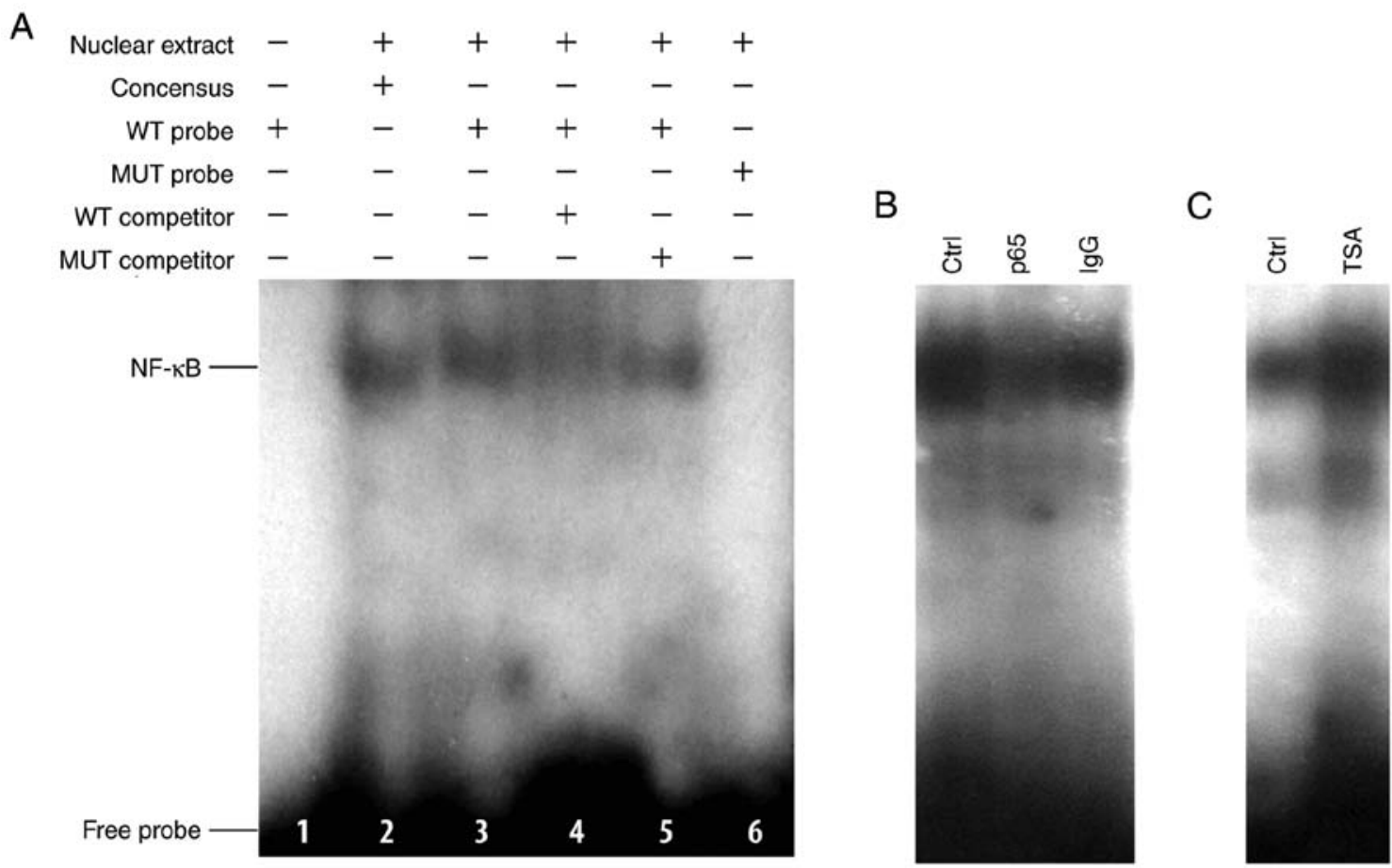

Figure 4. TSA increases the binding of NF- $\mathrm{kB}$ to its responsive element within DDAH2 promoter in vitro by electrophoresis mobility shift assay. (A) Identification of NF- $\mathrm{kB}$ binding to the DDAH2 promoter. Lane 1, WT probe without nuclear extract; lane 2, binding of the consensus probe to the nuclear extract; lanes 3 and 6, binding of WT and MUT probes to the nuclear extract, respectively; lanes 4 and 5, effect of WT or MUT unlabeled competitor on probe binding. (B) Blocking of NF- $\mathrm{kB}$ binding to WT probe using the p65 antibody. (C) Effect of TSA treatment on the binding of NF- $\mathrm{kB}$. DDAH2, dimethylarginine dimethylaminohydrolase 2; TSA, trichostatin A; WT, wild-type; MUT, mutant; ctrl, control.

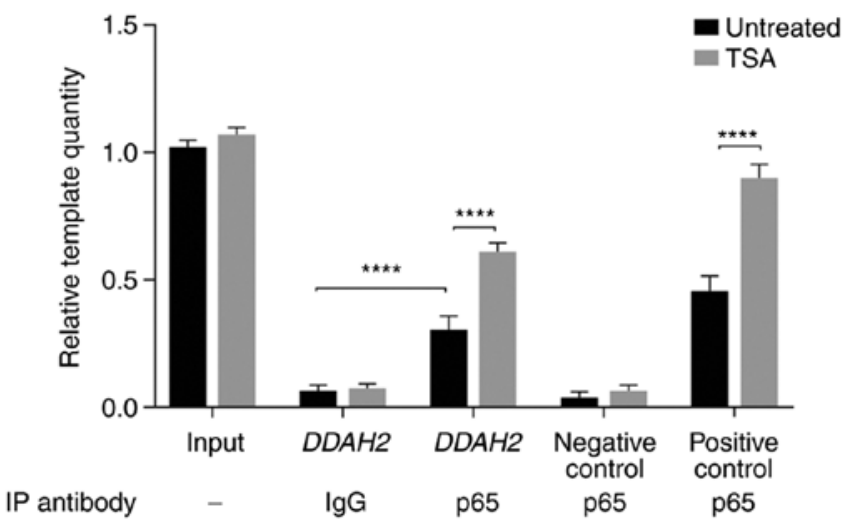

Figure 5. TSA increases the binding ability of NF- $\mathrm{kB}$ as shown using a chromatin immunoprecipitation assay. Lysates from 293 cells were immunoprecipitated with a p65 antibody or normal IgG. DNA fragments of the DDAH2 promoter containing the NF- $\kappa B$ responsive element were then amplified by quantitative PCR. The binding capacity was determined under untreated and TSA-treated conditions. Lysates that were not subjected to immunoprecipitation were used as the input control. A region within the DDAH2 promoter without a potential NF- $\mathrm{kB}$ responsive element was used as a negative control, and an neuronal nitric oxide synthase promoter region with a confirmed NF- $\kappa B$ site was used as a positive control. $n=3$. ${ }^{* * *} \mathrm{P}<0.0001$. DDAH2, dimethylarginine dimethylaminohydrolase 2; TSA, trichostatin A.

of non-histone proteins, the majority of which are involved in transcriptional regulation, were rapidly revealed to undergo acetylation, including p53, Tat and NF- $\kappa \mathrm{B}(15,33-35)$. Histone acetyltransferases (HATs) and histone deacetylases (HDACs) are involved in regulating the protein acetylation status (36). The balance between these two classes of enzymes is crucial in maintaining appropriate protein acetylation homeostasis. It has been reported that TSA specifically inhibits HDAC activity and recruits HATs in gene transcription processes, leading to the acetylation of histones and certain transcription factors $(16,25)$. Therefore, TSA has entered clinical trials for treating certain diseases, such as such as cancer and nerve degradation after brain injury $(25,37)$. Therefore, these aforementioned previous findings support the present findings that TSA-induced acetylation increased both DDAH2 mRNA and protein expression levels in 293 cells, which was in accordance with the reported effects of TSA on DDAH2 expression in trophoblasts (12).

$\mathrm{NF}-\kappa \mathrm{B}$ is an ubiquitously-expressed transcription factor that is involved in numerous processes in the kidney, including inflammation, endothelial function and cellular transformation (38). Therefore, the NF- $\mathrm{BB}$ signaling pathway has become a potential target for treatment of certain diseases. For example, $\mathrm{NF}-\kappa \mathrm{B}$ silencing in endothelial cells inhibited a signaling cascade leading to reduced hypertension-induced renal damage (39). It was previously shown that the acetyltransferase $\mathrm{p} 300$ complexes with $\mathrm{NF}-\kappa \mathrm{B}$ as a coactivator to acetylate NF- $\kappa \mathrm{B}$ as a HAT, resulting in increased acetylation of $N F-\kappa B$ p65 and p50 subunits, in turn activating the nNOS exon 1f promoter $(13,19)$. Deng and $\mathrm{Wu}(20)$ previously reported that p300 could acetylate the p50 subunit of $N F-\kappa B$, thereby increasing $N F-\kappa B$ binding affinity and NF- $\kappa \mathrm{B}$-mediated transactivation, which is essential for iNOS transcription. These findings indicate the importance of NF- $\kappa \mathrm{B}$ acetylation in NO modulation. Therefore, to elucidate the mechanism underlying the acetylation-regulated DDAH2 expression in renal cells, the present study focused on the role of NF- $\mathrm{NB}$ in this process. DDAH2 is transcribed into three transcripts due to three different transcription start sites. A number of studies have shown that certain polymorphisms within the 
DDAH2 core promoter can affect its basal transcription $(40,41)$. However, the structure of the DDAH2 promoter has not been fully elucidated. As a result, the 5'-region upstream sequences of all three of the transcripts were analyzed, where the analysis revealed a number of potential responsive elements of certain transcription factors, including CCAAT-enhancer-binding protein, GATA-binding factor 1, olfactory neuronal transcription factor 1 , activating protein 2 , specificity protein 1 , interferon consensus sequence-binding protein, $\mathrm{NF}-\kappa \mathrm{B}$, retinoid X receptor, ETS Like-1 protein, Yin Yang 1, nuclear factor-1, helix-loop-helix transcription factors E47, myoblast determination protein 1 , serum response factor and cytoplasmic polyadenylation elements binding protein (data not shown). Among them, a potential NF- $\mathrm{BB}$ site was located at the -1582 to -1573 region. EMSA and ChIP assays demonstrated that in 293 cells, p65 could specifically bind to the NF- $\kappa B$ response element site. In particular, mutations in the binding site blocked the binding of p65, markedly decreasing the promoter activity, suggesting a role of the $\mathrm{NF}-\kappa \mathrm{B}$ responsive element in regulating DDAH2 expression.

In addition, the present study showed that TSA treatment evidently induced the acetylation of $\mathrm{NF}-\kappa \mathrm{B}$ p 65 subunit. It has been previously suggested that increased acetylation of transcription factors may affect their subcellular distribution, stability, DNA binding affinity and transcriptional activity (42). Therefore, the effect of acetylation on the DNA binding ability of $\mathrm{NF}-\kappa \mathrm{B}$ and DDAH2 transactivation was investigated in the present study. EMSA and ChIP assays showed that p65 acetylation increased its binding ability to the DDAH2 promoter. Additionally, luciferase assays demonstrated that the promoter activity was increased by acetylation. However, luciferase activity was attenuated following mutations in the $\mathrm{NF}-\kappa \mathrm{B}$ responsive element, supporting the role of $\mathrm{NF}-\kappa \mathrm{B}$ acetylation in DDAH2 transactivation through its enhanced binding capacity. The results of the present study were in accordance with findings from a previous study showing that the cAMP response element-binding protein/p300-dependent acetylation of p65 at lys 310 was associated with $\mathrm{NF}-\kappa \mathrm{B}$ transcriptional activation in activated $\mathrm{B}$ cells (43). The possibility that the TSA-induced histone acetylation could also affect NF- $\kappa \mathrm{B}$ binding should not be completely excluded. However, this effect was found to be at least partially mediated by its induction through $\mathrm{NF}-\kappa \mathrm{B}$ acetylation. Furthermore, a minor increase in the activity of the DDAH2 promoter harboring mutations in the NF- $\kappa \mathrm{B}$ binding sites was observed in TSA-treated cells compared with that in the untreated control cells. This observation could result from the effect of other acetylated transcription factors, which could also bind to the DDAH2 promoter. Interestingly, following TSA treatment, changes in the activity of the DDAH2 promoter (1.6-fold to control), mRNA expression (2.2-fold to control) and protein levels (3.2-fold to control) were not completely parallel. This effect could be a result of post-transcriptional and post-translational regulation of DDAH2, such as the mRNA and protein degradation rates and translational efficiency. Although these regulatory mechanisms have not been previously reported in DDAH2, DDAH1 has been shown to be subject to post-transcriptional regulation through its $3^{\prime}$ untranslated region (44).

NO deficiency in the kidney is commonly observed in renal diseases, including diabetic and hypertensive nephropathy, obstructive nephropathy and glomerulosclerosis $(35,45)$. In addition, NO deficiency has been proposed to be the main mechanism of systemic hypertension $(45,46)$. NO insufficiency may be caused by the decreased abundance and activity of NOS and increase in the levels of the endogenous NOS inhibitor ADMA $(47,48)$. As aforementioned, NF- $\kappa$ B acetylation is involved in NOS regulation $(19,20)$. Taken together, the aforementioned findings indicated that $\mathrm{NF}-\kappa \mathrm{B}$ acetylation could modulate both NOS and DDAH systems, supporting its role in NO synthesis and providing the molecular basis for treating NO-related diseases by modulating NF- $\kappa \mathrm{B}$ acetylation. The possibility of treating certain renal disorders by changing the NF- $\kappa \mathrm{B}$ acetylation status has been previously discussed. Increased acetylation of p65 was observed in diabetic nephropathy and cisplatin-induced nephrotoxicity during chemotherapy in patients with cancer. Furthermore, overexpression of restored Sirtuin-1 deacetylase ameliorated the increased acetylation of p65, which attenuated renal cell damage and kidney injury $(29,30)$. However, Staab et al (49) reported that treatment with exogenous ADMA enhanced cigarette smoke-mediated $\mathrm{NF}-\kappa \mathrm{B}$ binding activity, indicating that the DDAH/ADMA axis could in turn affect NF- $\kappa \mathrm{B}$ signaling. Therefore, their reciprocal effects need further investigation prior their application as a therapeutic strategy for certain diseases.

A limitation of the current study was that although the immortalized 293 cell line derived from human embryonic kidney has been extensively used as models of human renal cells in in vitro studies, some evidence in the literature shows that 293 cells display genotypic and phenotypic characteristics that differ substantially from primary kidney cells $(50,51)$. Therefore, the current results need to be further confirmed on renal cell lines, such as HK-2 and podocytes as well.

Overall, the present study demonstrated that $\mathrm{NF}-\kappa \mathrm{B}$ acetylation could upregulate its binding affinity to the DDAH2 promoter, thus resulting in the augmentation of its transcriptional activity and DDAH2 expression in renal cells. These findings provided a possible mechanism underlying the regulation of NO production in renal cells and a potential target for treating certain NO-related renal disorders.

\section{Acknowledgements}

Not applicable.

\section{Funding}

The present study was supported by Natural Science Foundation of Liaoning Province (grant no. 2014021061) and National Natural Science Foundation of China (grant no. 30900807).

\section{Availability of data and materials}

The datasets used and/or analyzed during the current study are available from the corresponding author on reasonable request.

\section{Authors' contributions}

JL and LS performed all the experiments and analyzed the data. YL designed the study, supervised performance, interpreted the data and wrote and revised the manuscript. All authors read and approved the final manuscript. 


\section{Ethics approval and consent to participate}

Not applicable.

\section{Patient consent for publication}

Not applicable.

\section{Competing interests}

The authors declare that they have no competing interests.

\section{References}

1. Zou AP and Cowley AW Jr: Role of nitric oxide in the control of renal function and salt sensitivity. Curr Hypertens Rep 1: 178-186, 1999.

2. Monzon CM and Garvin JL: Nitric oxide decreases the permselectivity of the paracellular pathway in thick ascending limbs. Hypertension 65: 1245-1250, 2015.

3. Garcia NH, Stoos BA, Carretero OA and Garvin JL: Mechanism of the nitric oxide-induced blockade of collecting duct water permeability. Hypertension 27: 679-683, 1996.

4. Tain YL and Hsu CN: Toxic dimethylarginines: Asymmetric dimethylarginine (ADMA) and symmetric dimethylarginine (SDMA). Toxins (Basel) 9: 92, 2017.

5. Jayachandran I, Sundararajan S, Paramasivam P, Venkatesan B, Subramanian SC, Balasubramanyam M, Mohan V and Manickam N: Association of circulatory asymmetric dimethylarginine (ADMA) with diabetic nephropathy in Asian Indians and its causative role in renal cell injury. Clinical Biochem 50 835-842, 2017

6. Palm F, Onozato ML, Luo Z and Wilcox CS: Dimethylarginine dimethylaminohydrolase (DDAH): Expression, regulation, and function in the cardiovascular and renal systems. Am J Physiol Heart Circ Physiol 293: H3227-H3245, 2007.

7. Tojo A, Welch WJ, Bremer V, Kimoto M, Kimura K, Omata M, Ogawa T, Vallance P and Wilcox CS: Colocalization of demethylating enzymes and NOS and functional effects of methylarginines in rat kidney. Kidney Int 52: 1593-1601, 1997.

8. Nijveldt RJ, Teerlink T, Siroen MP, van Lambalgen AA, Rauwerda JA and van Leeuwen PA: The liver is an important organ in the metabolism of asymmetrical dimethylarginine (ADMA). Clin Nutr 22: 17-22, 2003.

9. Förstermann U and Sessa WC: Nitric oxide synthases: Regulation and function. Eur Heart J 33: 829-37, 2012.

10. Zhang Z, Zhu LL, Jiang HS, Chen H, Chen Y and Dai YT: Demethylation treatment restores erectile function in a rat model of hyperhomocysteinemia. Asian J Androl 18: 763-768, 2016.

11. Zhang JG, Liu JX, Li ZH, Wang LZ, Jiang YD and Wang SR: Dysfunction of endothelial NO system originated from homocysteine-induced aberrant methylation pattern in promoter region of DDAH2 gene. Chin Med J 120: 2132-7, 2007.

12. Tomikawa J, Fukatsu K, Tanaka S and Shiota K: DNA methylation-dependent epigenetic regulation of dimethylarginine dimethylaminohydrolase 2 gene in trophoblast cell lineage. J Biol Chem 281: 12163-12169, 2006.

13. Li Y, Li C, Sun L, Chu G, Li J, Chen F, Li G and Zhao Y: Role of p300 in regulating neuronal nitric oxide synthase gene expression through nuclear factor- $\mathrm{kB}$-mediated way in neuronal cells. Neuroscience 248: 681-689, 2013.

14. Chen J, Zhang J, Shaik NF, Yi B, Wei X, Yang XF, Naik UP, Summer R, Yan G, Xu X and Sun J: The histone deacetylase inhibitor tubacin mitigates endothelial dysfunction by up-regulating the expression of endothelial nitric oxide synthase. J Biol Chem 294: 19565-19576, 2019.

15. Chen L, Fischle W, Verdin E and Greene WC: Duration of nuclear NF-kappaB action regulated by reversible acetylation. Science 293: 1653-1657, 2001.

16. Huang W, Zhao S, Ammanamanchi S, Brattain M, Venkatasubbarao K and Freeman JW: Trichostatin A induces transforming growth factor beta type II receptor promoter activity and acetylation of Sp1 by recruitment of $\mathrm{PCAF} / \mathrm{p} 300$ to a Sp1.NF-Y complex. J Biol Chem 280: 10047-10054, 2005.
17. Izumi $H$, Ohta $R$, Nagatani $G$, Ise $T$, Nakayama $Y$, Nomoto $M$ and Kohno K: p300/CBP-associated factor (P/CAF) interacts with nuclear respiratory factor-1 to regulate the UDP-N-acetyl-alpha-d-galactosamine: Polypeptide $\mathrm{N}$-acetylgalactosaminyltransferase-3 gene. Biochem J 373 713-722, 2003

18. Lee JS, Galvin KM, See RH, Eckner R, Livingston D, Moran E and Shi Y: Relief of YY1 transcriptional repression by adenovirus E1A is mediated by E1A-associated protein p300. Genes Dev 9: 1188-1198, 1995.

19. Li Y, Zhao Y, Li G, Wang J, Li T, Li W and Lu J: Regulation of neuronal nitric oxide synthase exon if gene expression by nuclear factor-kappaB acetylation in human neuroblastoma cells. J Neurochem 101: 1194-1204, 2007.

20. Deng WG and Wu KK: Regulation of inducible nitric oxide synthase expression by p300 and p50 acetylation. J Immunol 171: 6581-6588, 2003.

21. Livak KJ and Schmittgen TD: Analysis of relative gene expression data using real-time quantitative PCR and the 2(-Delta Delta $\mathrm{C}(\mathrm{T})$ ) method. Methods 25: 402-408, 2001

22. Korneluk RG, Quan F and Gravel RA: Rapid and reliable dideoxy sequencing of double-stranded DNA. Gene 40: 317-323, 1985

23. Sengüven B, Baris E, Oygur T and Berktas M: Comparison of methods for the extraction of DNA from formalin-fixed, paraffin-embedded archival tissues. Int J Med Sci 11: 494-499, 2014.

24. Haring M, Offermann S, Danker T, Horst I, Peterhansel C and Stam M: Chromatin immunoprecipitation: Optimization, quantitative analysis and data normalization. Plant Methods 3: 11, 2007.

25. Yoshida M, Kijima M, Akita M and Beppu T: Potent and specific inhibition of mammalian histone deacetylase both in vivo and in vitro by trichostatin A. J Biol Chem 265: 17174-17179, 1990.

26. Guijarro C and Egido J: Transcription factor-kappa B (NF-kappa B) and renal disease. Kidney Int 59: 415-424, 2001.

27. Queisser N and Schupp N: Aldosterone, oxidative stress, and NF- $\kappa \mathrm{B}$ activation in hypertension-related cardiovascular and renal diseases. Free Radic Biol Med 53: 314-327, 2012.

28. Shang G, Gao P, Zhao Z, Chen Q, Jiang T, Zhang N and Li H: 3,5-Diiodo-l-thyronine ameliorates diabetic nephropathy in streptozotocin-induced diabetic rats. Biochim Biophys Acta 1832: 674-684, 2013.

29. Liu R, Zhong Y, Li X, Chen H, Jim B, Zhou MM, Chuang PY and He JC: Role of transcription factor acetylation in diabetic kidney disease. Diabetes 63: 2440-2453, 2014.

30. Jung YJ, Lee JE, Lee AS, Kang KP, Lee S, Park SK, Lee SY, Han MK, Kim DH and Kim W: SIRT1 overexpression decreases cisplatin-induced acetylation of NF- $\mathrm{KB}$ p65 subunit and cytotoxicity in renal proximal tubule cells. Biochem Biophys Res Commun 419: 206-210, 2012.

31. Turner BM, Birley AJ and Lavender J: Histone $\mathrm{H} 4$ isoforms acetylated at specific lysine residues define individual chromosomes and chromatin domains in Drosophila polytene nuclei. Cell 69: 375-384, 1992.

32. Turner BM and Fellows G: Specific antibodies reveal ordered and cell-cycle-related use of histone- $\mathrm{H} 4$ acetylation sites in mammalian cells. Eur J Biochem 179: 131-139, 1989.

33. Verdin E and Ott M: 50 years of protein acetylation: From gene regulation to epigenetics, metabolism and beyond. Nat Rev Mol Cell Biol 16: 258-264, 2015.

34. Gu W and Roeder RG: Activation of p53 sequence-specific DNA binding by acetylation of the p53 C-terminal domain. Cell 90: 595-606, 1997.

35. Kiernan RE, Vanhulle C, Schiltz L, Adam E, Xiao H, Maudoux F, Calomme C, Burny A, Nakatani Y, Jeang KT, et al: HIV-1 tat transcriptional activity is regulated by acetylation. EMBO J 18: 6106-6118, 1999.

36. Yang XJ and Seto E: HATs and HDACs: From structure, function and regulation to novel strategies for therapy and prevention. Oncogene 26: 5310-5318, 2007.

37. Huynh NC, Everts V and Ampornaramveth RS: Histone deacetylases and their roles in mineralized tissue regeneration. Bone Rep 7: 33-40, 2017

38. Zhang $\mathrm{H}$ and Sun SC: $\mathrm{NF}-\kappa \mathrm{B}$ in inflammation and renal diseases. Cell Biosci 5:63, 2015

39. Henke N, Schmidt-Ullrich R, Dechend R, Park JK, Qadri F, Wellner M, Obst M, Gross V, Dietz R, Luft FC, et al: Vascular endothelial cell-specific NF-kappaB suppression attenuates hypertension-induced renal damage. Circ Res 101: 268-276, 2007. 
40. Jones LC, Tran CT, Leiper JM, Hingorani AD and Vallance P Common genetic variation in a basal promoter element alters DDAH2 expression in endothelial cells. Biochem Biophys Res Commun 310: 836-843, 2003.

41. Andreozzi F, Presta I, Mannino GC, Scarpelli D, Di Silvestre S, Di Pietro N, Succurro E, Sciacqua A, Pandolfi A, Consoli A, et al: A functional variant of the dimethylarginine dimethylaminohydrolase-2 gene is associated with insulin sensitivity. PLoS One 7: e36224, 2012.

42. Park JM, Jo SH, Kim MY, Kim TH and Ahn YH: Role of transcription factor acetylation in the regulation of metabolic homeostasis. Protein Cell 6: 804-813, 2015.

43. Ma Z, Chalkley RJ and Vosseller K: Hyper-O-GlcNAcylation activates nuclear factor $\kappa$-light-chain-enhancer of activated $B$ cells $(\mathrm{NF}-\mathrm{\kappa} B$ ) signaling through interplay with phosphorylation and acetylation. J Biol Chem 292: 9150-9163, 2017.

44. Balasubramanian V, Mehta G, Jones H, Sharma V, Davies NA Jalan R and Mookerjee RP: Post-transcriptional regulation of hepatic DDAH1 with TNF blockade leads to improved eNOS function and reduced portal pressure in cirrhotic rats. Sci Rep 7: 17900,2017

45. Hsu CN and Tain YL: Regulation of nitric oxide production in the developmental programming of hypertension and kidney disease. Int J Mol Sci 20: 681, 2019.

46. Ahmad A, Dempsey SK, Daneva Z, Azam M, Li N, Li PL and Ritter JK: Role of Nitric Oxide in the Cardiovascular and Renal Systems. Int J Mo Sci 19: 2605, 2018.
47. Lin HH, Lee TS, Lin SJ, Yeh YC, Lu TM and Hsu CP: DDAH-2 alleviates contrast medium iopromide-induced acute kidney injury through nitric oxide synthase. Clin Sci (Lond) 133: 2361-2378, 2019.

48. Wagner L, Riggleman A, Erdely A, Couser W and Baylis C: Reduced nitric oxide synthase activity in rats with chronic renal disease due to glomerulonephritis. Kidney Int 62: 532-536, 2002.

49. Staab EB, Weigel J, Xiao F, Madayiputhiya N, Wyatt TA and Wells SM: Asymmetric dimethyl-arginine metabolism in a murine model of cigarette smoke-mediated lung inflammation. J Immunotoxicol 12: 273-282, 2015.

50. Lin YC, Boone M, Meuris L, Lemmens I, Van Roy N, Soete A, Reumers J, Moisse M, Plaisance S, Drmanac R, et al: Genome dynamics of the human embryonic kidney 293 lineage in response to cell biology manipulations. Nat Commun 5: 4767, 2014.

51. Stepanenko AA and Dmitrenko VV: HEK293 in cell biology and cancer research: Phenotype, karyotype, tumorigenicity, and stress-induced genome-phenotype evolution. Gene 569: 182-190, 2015.

This work is licensed under a Creative Commons Attribution-NonCommercial-NoDerivatives 4.0 International (CC BY-NC-ND 4.0) License. 